\title{
EFEKTIVITAS VEGETASI UNTUK PENURUNAN KADAR KARBON MONOKSIDA (CO) DAN NITROGEN DIOKSIDA (NO
}

\author{
1)Hendra Purwanto Utomo, ${ }^{2}$ Rhenny Ratnawati \\ 1) 2)Program Studi Teknik Lingkungan, Fakultas Teknik, Universitas PGRI Adi Buana Surabaya \\ E-mail: ratnawati@unipasby.ac.id
}

\begin{abstract}
Abstrak
Salah satu fungsi tumbuhan mampu membersihkan udara dari partikel debu dan bahan kimia yang berbahaya yang berasal dari emisi kendaraan bermotor. penelitian ini menggunakan reaktor/rumah tumbuhan yang berbentuk kubus berukuran panjang $0,5 \mathrm{~m}$; lebar $0,5 \mathrm{~m}$; tinggi $1,5 \mathrm{~m}$ dan dipapari emisi kendaraan bermotor Vespa tahun 1983 dengan bahan bakar bensin yang dihubungkan kedalam rumah tumbuhan selama 15, 10 dan 5 menit. Metode pengambilan sampel karbon monoksida $(\mathrm{CO})$ dan nitrogen dioksida $\left(\mathrm{NO}_{2}\right)$ menggunakan alat gas analyzer. Efisiensi penurunan kadar CO menggunakan tumbuhan pucuk merah dengan waktu pemaparan 15,10,dan 5 menit secara berturut-turut yaitu sebesar 10,64\%, 8,51 \%, dan 7,74 \%. Sedangkan efisiensi penurunan kadar CO menggunakan tumbuhan glodokan tiang secara berturut-turut sebesar 13,19 $\%, 11,59 \%$, dan $12,03 \%$. Efisiensi kadar $\mathrm{NO}_{2}$ menggunakan tumbuhan pucuk merah dengan waktu pemaparan yang sama sebesar $25,00 \%, 20,00 \%$, dan $33,33 \%$. Sedangkan pada tumbuhan glodokan diperoleh nilai efisiensi penurunan kadar $\mathrm{NO}_{2}$ sebesar 50\%,50\%,dan 33\%.
\end{abstract}

Kata kunci: glodokan tiang, Karbon monoksida (CO), Nitrogen dioksida $\left(\mathrm{NO}^{2}\right)$, pucuk merah

\begin{abstract}
One of the functions of plants is to clean the air from dust particles and harmful chemicals that come from motorized vehicle emissions. This research uses a reactor / plant house in the form of a cube with a length of $0.5 \mathrm{~m} ; 0.5 \mathrm{~m}$ width; $1.5 \mathrm{~m}$ high and exposed to 1983 Vespa motor vehicle emissions with gasoline connected to the plant house for 15, 10 and 5 minutes, samples were taken after contact with plants for 0, 1, 2, 3, 4 consecutive days. The method of sampling carbon monoxide (CO) and nitrogen dioxide $\left(\mathrm{NO}_{2}\right)$ using a gas analyzer. The efficiency of reducing $\mathrm{CO}$ levels using red shoot plants with an exposure time of 15.10 and 5 minutes respectively were $10.64 \%, 8.51 \%$, and $7.74 \%$. Meanwhile, the efficiency of reducing CO levels using pole glowing plants was $13.19 \%, 11.59 \%$, and $12.03 \%$, respectively. The efficiency of NO2 levels used red shoot plants with the same exposure time of $25.00 \%, 20.00 \%$, and $33.33 \%$. Whereas in the glodokan plant, the efficiency value of NO2 reduction was $50 \%, 50 \%$, and $33 \%$.
\end{abstract}

Keywords: Carbon monoxide (CO), Nitrogen dioxide ( $\mathrm{NO}_{2}$ ), Plant Shoots red (Syzygium Oleana), Plant Glodokan Pole (Polyalthia Longifolia)

\section{PENDAhUluaN}

Dalam kehidupan udara merupakan salah satu faktor penting. Namun, pada saat ini udara semakin memburuk dikarenakan semakin banyak kendaraan bermotor dan semakin berkembangnya aktivitas industri. Udara yang bercampur dengan zat-zat berbahaya dapat mengganggu kesehatan seperti terganggunya sistem pernafasan, merusak sistem syaraf dan berbagai penyakit lain (Momongan 2016). Secara umum ada 2 faktor yang menjadi sumber pencemaran udara yaitu sumber alamiah dan sumber dari kegiatan manusia. Salah satu sumber pencemar udara adalah kendaraan bermotor. Menurut Badan Pusat Statistik, hingga tahun 2017 jumlah kendaraan bermotor di Indonesia berjumlah 138.556 .669 yang tersebar di 
berbagai penjuru negeri mulai dari kota-kota besar sampai pedesaan. Di Surabaya, setiap tahun terjadi pertambahan jumlah kendaraan bermotor antara $7-11 \%$, sedangkan untuk pembangunan ruas jalan raya hanya berkisar $1 \%$ (Rachmaniyah dkk 2017). Emisi kendaraan bermotor mengandung racun yang berbahaya bagi lingkungan. Bahan pencemar yang terkandung dalam gas buang kendaraan bermotor adalah karbon monoksida (CO), berbagai senyawa hidrokarbon ( $\mathrm{HC})$, nitrogen dioksida $\left(\mathrm{NO}_{2}\right)$, sulfur dioksida $\left(\mathrm{SO}_{2}\right)$ dan partikulat debu termasuk timbal (Mirawati dkk., 2016).

Pencemaran udara adalah bertambahnya kadar gas atau debu hingga melebihi baku mutu. Pada umumnya polutan berupa debu dan gas yang berasal dari kegiatan proses pembakaran mesin industri dan kendaraan bermotor (Hardiyanti 2017). Zat zat pencemaran udara ada beberapa macam antara lain: $\mathrm{CO}$, SOx, NOx, dan partikulat. kadar $\mathrm{NO}_{2}$, di udara di perkotaan polusi udara lebih besar dari pada di daerah pedesaan yang mempunyai penduduk tidak terlalu banyak. Hal ini dapat terjadi dikarenakan aktivitas manusia di daerah perkotaan yang menunjang kehidupan sehari-hari akan menambah kardar $\mathrm{NO}_{2}$ di udara seperti kendaraan bermotor, genset, pembangkit listrik, pembakaran sampah dan lain-lain (Riani 2017). Gas $\mathrm{NO}_{2}$ lebih toksik dari pada gas $\mathrm{NO}$, organ tubuh yang paling mudah terpapar oleh gas $\mathrm{NO}_{2}$ adalah paru-paru. Gas ini dapat menyebabkan pembengkakan paru-paru sehingga dapat menyebabkan sulit bernafas bahkan bisa menyebabkan kematian. Dampak gas $\mathrm{NO}_{2}$ sendiri terhadap lingkungan sama halnya dengan gas $\mathrm{SO}_{2}$ yang dapat menyebabkan hujam asam di atmosfer (Riani 2017). Karbon monoksida (CO) adalah gas yang dihasilkan dari pembakaran yang tidak sempurna kendaraan bermotor (Prodjosantoso 2011).

Penelitian yang dilakuan Agustin (2018) dengan metode di dalam rumah tumbuhan yang yang di papari $\mathrm{SO}_{2}$ dan $\mathrm{NO}_{2}$ dari kendaraan bermotor dengan waktu pemaparan 5 menit, 10 menit dan waktu pengambilan sampel dilakukan setiap minggu selama 1 bulan menunjukkan kadar $\mathrm{SO}_{2}$ akhir menggunakan tumbuhan Puring (Codiaeum interuptum) pada waktu pemaparan 0 menit, 5 menit, 10 menit berturut-turut adaah 0,025 ppm (3,84\%); 0,031 ppm (24,39); dan 0,039 ppm (22\%). Sedangkan, kadar $\mathrm{NO}_{2}$ akhir menggunakan tumbuhan Akalipa Merah (Acalypa wilkesiana) pada waktu pemaparan 0 menit, 5 menit, 10 menit berturut-turut adalah $0,375 \mathrm{ppm}(0,53 \%) ; 0,890 \mathrm{ppm}$ $(1,66 \%) ; 0,954$ ppm (2,15\%). Sedangkan Palureng (2017) melakukan penelitian dengan metode mengukur kadar TSP dengan alat HVAS dan juga dilakukan perhitungan volume kendaraan yang melintas selama waktu pengukuran, pengambilan sampel dilakukan di jalan raya dan di belakang vegetasi sehingga dapat mengetahui sebera besar efektifitas penurunannya menunjukan tumbuhan pucuk merah (Syzygium oleana) dapat menjerap total suspended partikulat (TSP) dengan konsentrasi 93,1915 $\mu \mathrm{g} / \mathrm{Nm}^{3}$ atau sebesar $32,65 \%$ dan tumbuhan ketapang dapat menjerap sebesar 53,37\%. Penelitian bertujuan untuk: 1. mengetahui tingkat penurunan kadar karbon monoksida (CO) dan nitrogen dioksida $\left(\mathrm{NO}_{2}\right)$ menggunakan tumbuhan pucuk merah (Syzygium oleana) dan glodokan tiang (Polyalthia longifolia) dan 2. mengetahui tingkat efektifitas antara pucuk merah (Syzygium oleana) dan glodokan tiang (Polyalthia longifolia).

\section{METODOLOGI}

\section{Persiapan Alat dan Bahan}

Reaktor yang digunakan dalam penelitian ini menggunakan rumah tumbuhan yang mempunya spesifikasi berbentuk kubus yang mempunyai panjang $50 \mathrm{~cm}$, lebar $50 \mathrm{~cm}$ dan tinggi $150 \mathrm{~cm}$. Rangka reaktor terbuat dari kayu yang potong dan dibentuk sedimikian rupa lalu di bungkus dengan plastic diberi lubang untuk memasukan emisi kendaraan. Aliran gas dengan menggunakan selang plastik dengan ukuran diameter 1.5 $\mathrm{cm}$. Pada bagian bawah dinding plastik diberikan lubang yang dapat di buka dan tutup untuk menaruh alat $\mathrm{CO}$ detector. Sumber pencemar berasal dari emisi kendaraan bermotor Honda C70 tahun 1997 dengan bahan bakar Premium. 


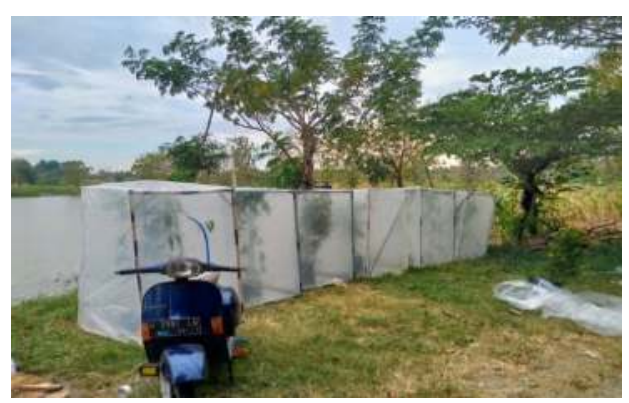

Gambar 1 Reaktor/rumah tumbuhan

\section{Metode Pengumpulan Data}

Dalam satu reaktor terdapat 2-3 tumbuhan. Sebelum perlakuan pemaparan semua luas permukaan daun tumbuhan disamakan yaitu $702 \mathrm{~cm}^{2}$ untuk masingmasing reaktor. Penyiraman tumbuhan dengan volume air $250 \mathrm{~mL} /$ hari dan dilakukan setiap hari pada waktu sore hari. Waktu pemaparan selama $15,10,5$ menit dan pengambilan sampel dilakukan menggunakan metode Direct reading gas detector pada 0,1 , 2, 3, 4 hari setelah kontak dengan tumbuhan. Lokasi penelitian ini berada di luar ruangan Jl. Niaga RT 01 RW 02, kelurahan Sentanan, kecamatan Kranggan, Kota Mojokerto. Gtabel 1 merupakan jenis tumbuhan dan waktu pemaparan.

Tabel 1. Kode Reaktor dan Variabel

\begin{tabular}{ccc}
\hline $\begin{array}{c}\text { Kode } \\
\text { Reaktor }\end{array}$ & Tumbuhan & $\begin{array}{c}\text { Waktu } \\
\text { pemaparan } \\
\text { (menit) }\end{array}$ \\
\hline 1 & Glodokan tiang & 15 \\
2 & Pucuk merah & 15 \\
3 & Glodokan tiang & 10 \\
4 & Pucuk merah & 10 \\
5 & Glodokan tiang & 5 \\
6 & Pucuk merah & 5 \\
\hline
\end{tabular}

\section{Analisis Data}

Analisis data dilakukan dengan cara membandingkan penurunan gas buang dengan menggunakan media tumbuhan. Indikator yang digunakan untuk mengetahui hasil adalah hasil penurunan kadar gas karbon monoksida (CO) dan nitrogen dioksida $\left(\mathrm{NO}_{2}\right)$. Menghitung efektifitas penurunan kadar $\mathrm{CO} /$ $\mathrm{NO}_{2}$ dengan persamaan berikut

$$
\text { Efektivitas }(\%)=\frac{\text { K. Awal }- \text { K. Akhir }}{\text { K. Awal }} x 100
$$

\section{HASIL DAN PEMBAHASAN}

\section{Penurunan Kadar CO}

Dari hasil pengambilan data selama 5 hari menunjukan kadar karbon monoksida (CO) pada pada reaktor 1,3,5 menggunakan tumbuhan glodokan tiang (Polyalthia longifolia) terjadi penurunan kadar Karbon monoksida (CO) dengan waktu pemaparan $15,10,5$ menit dan waktu kontak selama $0-4$ hari dengan kadar karbon monoksida $(\mathrm{CO})$ awal 3010, 2476, 1903 ppm menjadi kadar karbon monoksida (CO) akhir sebesar 2613, 2189, 1674 ppm. Sedangkan penurunan kadar karbon mononsidak (CO) pada reaktor 2,4,6 menggunakan tumbuhan pucuk merah (Syzygium oleana) dengan waktu pemaparan 15,10,5 menit dengan kadar CO awal 2961, 2490, 1899 ppm dan waktu kontak selama 0-4 hari terjadi penurunan kadar $\mathrm{CO}$ menjadi 2646, 2278, 1752 ppm. Adapun grafik penurunan kadar $\mathrm{CO}$ dapat dilihat pada Gambar 2.

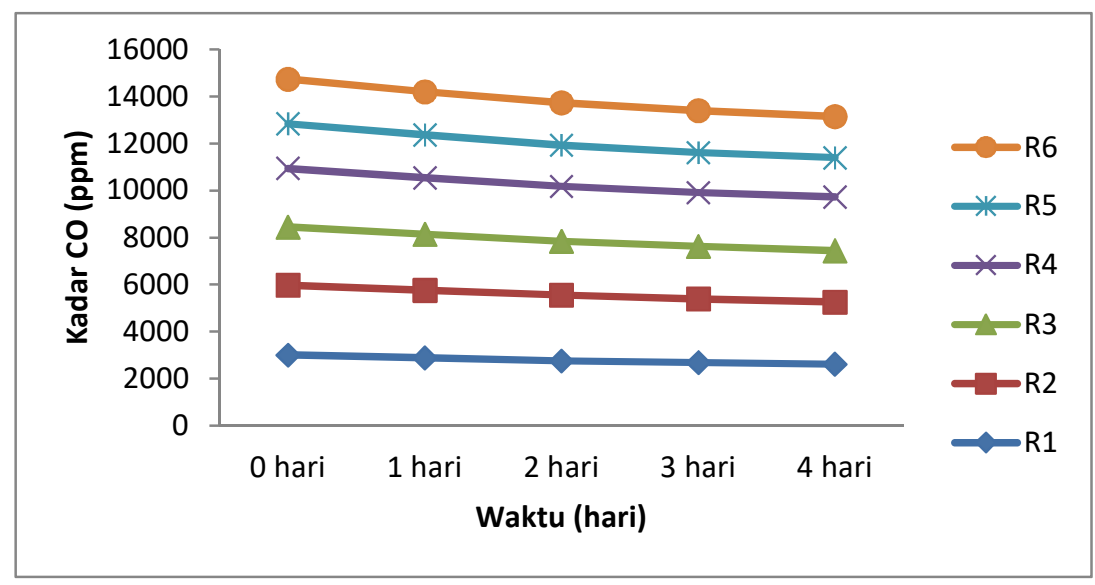


Penurunan kadar $\mathrm{NO}_{2}$

Penurunan kadar $\mathrm{NO}_{2}$ pada reakto 1,3,5 menggunakan tumbuhan glodokan tiang (Polyalthia longifolia) dengan waktu pemaparan 15,10,5 menit dengan kadar $\mathrm{NO}_{2}$ awal 8,6,3 ppm dan waktu kontak selama 0-4 hari menjadi 4,3,2 ppm. Sedangkan untuk
Gambar 2 Grafik penurunan kadar CO

penurunan kadar $\mathrm{NO}_{2}$ pada reaktor 2,4,6 menggunakan tumbuhan pucuk merah (Syzygium oleana) dengan waktu pemaparan 15,10,5 menit dengan kadar $\mathrm{NO}_{2}$ awal 8,5,3 ppm dan waktu kontak selama 0-4 hari menjadi 6,4,2 ppm. Adapun grafik penurunan kadar $\mathrm{NO}_{2}$ dapat dilihat pada Gambar 3.

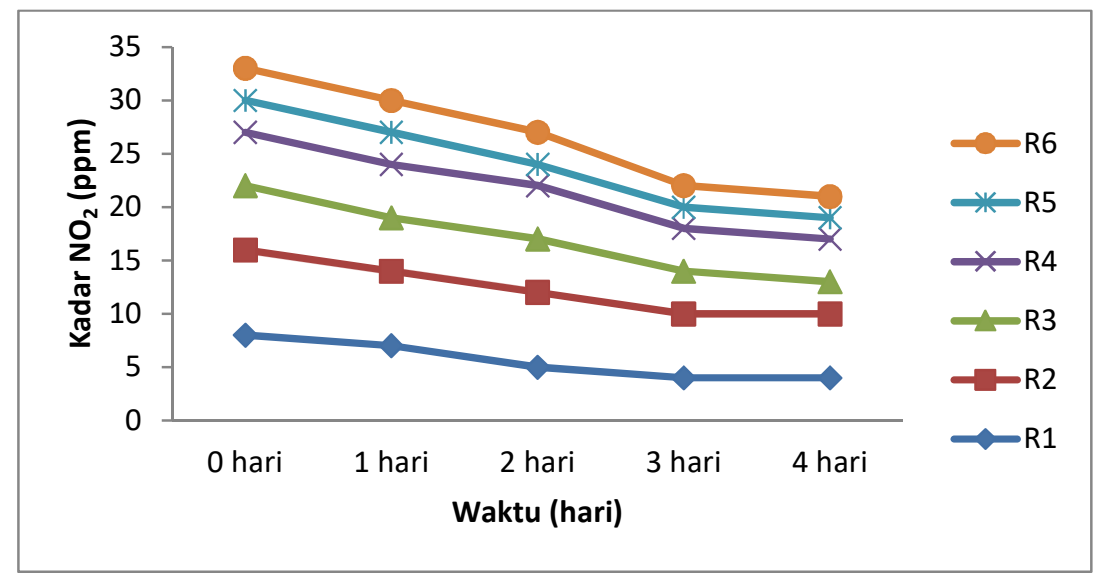

Gambar 3. Grafik penurunan kadar $\mathrm{NO}_{2}$

Dari penelitian selama 5 hari terdapat hasil, penurunan kadar $\mathrm{CO}$ dengan waktu pemaparan 15, 10, 5 menit dengan kadar $\mathrm{CO}$ awal 3010, 2476, 1903 ppm dan waktu kontak selama 0-4 hari menggunakan tumbuhan glodokan tiang (Polyalthia longifolia) terdapat penurunan kadar CO 2613, 2189, 1674 atau terjadi penurunan sebesar 13,19\%, $11,59 \%, \quad 12,03 \%$ dari kadar CO awal. Sedangkan penurunan kadar CO menggunakan tumbuhan pucuk merah (Syzygium oleana) dengan waktu pemaparan 15,10,5 menit dengan kadar $\mathrm{CO}$ awal 2961, 2490, 1899 ppm dan waktu kontak selama 0-4 hari terjadi penurunan kadar $\mathrm{CO}$ menjadi 2646, 2278, 1752 atau terjadi punurunan akhir sebesar 10,64\%, 8,51\%, 7,74\%. penurunan kadar $\mathrm{NO}_{2}$ menggunakan tumbuhan glodokan tiang (Polyalthia longifolia) dengan waktu pemaparan 15,10,5 menit dengan kadar $\mathrm{NO}_{2}$ awal 8, 6, 3 ppm dan waktu kontak selama 0 4 hari menjadi 4, 3, $2 \mathrm{ppm}$ atau terjadi penurunan sebesar $50 \%, 50 \%, 33 \%$. Sedangkan Untuk penurunan kadar $\mathrm{NO}_{2}$ menggunakan tumbuhan pucuk merah (Syzygium oleana) dengan waktu pemaparan 15, 10, 5 menit dengan kadar $\mathrm{NO}_{2}$ awal 8, 5, 3 ppm dan waktu kontak selama 0-4 hari menjadi 6, 4, 2 ppm atau terjadi penurunan sebesar $25,00 \%, \quad 20,00 \%, 33,33 \%$. Kadar Karbon monoksida (CO) dan Nitrogen Dioksida $\left(\mathrm{NO}_{2}\right)$ pada tumbuhan dapat mengalami penurunan karena proses penguraian secara alami. Menurut Santoso (2011) gas - gas di udara akan didifusikan ke dalam daun melalui stomata (mulut daun) pada proses fotosintesis atau terdeposisi oleh air kemudian didifusikan oleh akar tanaman. Gas pencemar yang masuk ke jaringan daun melalui lubang stomata yang berada pada epidermis atas. Epidermis adalah target utama dari polutan udara, dimana polutan pertama masuk melalui stomata.

Dalam penelitian ini menunjukan bahwa tumbuhan glodokan tiang (Polyalthia longifolia) memiliki tingkat penyerapan $\mathrm{CO}$ dan $\mathrm{NO}_{2}$ yang lebih tinggi sebesar 13,19\% untuk penurunan $\mathrm{CO}$ dan $50 \%$ untuk penurunan $\mathrm{NO}_{2}$. Sedangkan tumbuhan pucuk merah (Syzygium oleana) mampu menurunkan kadar $\mathrm{CO}$ paling tinggi $10,64 \%$ dan kadar $\mathrm{NO}_{2}$ tertinggi sebesar $33,33 \%$. Hal ini disebabkan karena stomata tumbuhan glodokan tiang (Polyalthia longifolia) 19,96 $\mu \mathrm{m}$, panjang $25,9 \mu \mathrm{m}$, sedangkan stomata tumbuhan pucuk merah (Syzygium oleana) 
lebar $12,95 \mu \mathrm{m}$ panjang $13,76 \mu \mathrm{m}$ Stomata glodokan tiang lebar. Tumbuhan glodokan tiang (Polyalthia longifolia) memiliki bentuk fisik yang kuat, tinggi, bentuk permukaan daun sedikit kasar dan sedikit lengket seperti yang dijelaskan (Santoso, 2011) Tumbuhan memiliki tajuk rimbun, tidak gugur daun, tumbuhannya tinggi. Karakter khusus tumbuhan yang mempunyai kemampuan tinggi mengurangi polutan partikel memiliki ciri daun, memiliki bulu halus, permukaan daun kasar, daun bersisik, tepi daun bergigi, daun jarum, daun yang permukaannya bersifat lengket, ini efektif menyerap polutan. Sejalan dengan penelitian yang dilakukan (Kondorura, 2018) bahwa tumbuhan glodokan tiang (Polyalthia longifolia) mampu menyerap Karbon monoksida (CO) sebesar $0.95814 \mathrm{~kg} / \mathrm{jam}$ sedangkan tumbuhan pucuk merah (Syzygium oleana) yang hanya mampu menyerap $0.02409 \mathrm{~kg} / \mathrm{jam}$. Serta ada lagi kajian yang menunjukan efektifitas tumbuhan glodokan tiang (Polyalthia longifolia) dapat menyerap kadar CO 393.125,59 kg/tahun sedangkan pucuk merah (Syzygium oleana) hanya mampu menyerap kadar CO 84.405,24 $\mathrm{kg} /$ tahun (Wakhid 2018).

Menurut Agustin (2018) bahwa semakin lama waktu kontaknya maka akan semakin efektif mereduksi polutan. Hal ini disebabkan tanaman yang berada pada daerah terpapar polusi tinggi cenderung akan meningkatkan jumlah stomata sebagai respon untuk mempertahankan diri. Peningkatan jumlah stomata tersebut membantu dalam penyerapan polusi untuk kegiatan fotosintesis.

\section{KESIMPULAN}

Pada penelitian ini dapat disimpulkan sebagai berikut:

1. Efektifitas penurunan kadar $\mathrm{CO}$ menggunakan tumbuhan pucuk merah (Syzygium oleana) dengan waktu pemaparan 15,10,5 menit dengan kadar CO awal 2961, 2490, 1899 ppm dan waktu kontak selama $0-4$ hari nilai efektifitas akhir sebesar 10,64\%, 8,51\%, $7,74 \%$. Sedangkan efektifitas penurunan kadar CO dengan waktu pemaparan 15 , 10, 5 menit dengan kadar CO awal 3010, 2476, 1903 ppm dan waktu kontak selama 0-4 hari menggunakan tumbuhan glodokan tiang (Polyalthia longifolia) nilai efektifitas sebesar $13,19 \%, 11,59 \%$, $12,03 \%$.

2. Efektifitas penurunan kadar $\mathrm{NO}_{2}$ menggunakan tumbuhan pucuk merah (Syzygium oleana) dengan waktu pemaparan 15, 10, dan 5 menit dengan kadar NO2 awal 8,5,3 ppm dan waktu kontak selama 0-4 hari nilai efektifitas sebesar $25,00 \%, \quad 20,00 \%, \quad 33,33 \%$. Efektifitas penurunan kadar $\mathrm{NO}_{2}$ menggunakan tumbuhan glodokan tiang (Polyalthia longifolia) dengan waktu pemaparan 15, 10, dan 5 menit dengan kadar $\mathrm{NO}_{2}$ awal 8,6,3 ppm dan waktu kontak selama 0-4 hari nilai efektifitas sebesar 50\%, 50\%, 33\%.

3. Tumbuhan glodokan tiang (Polyalthia longifolia) tingkat penyerapannya untuk mengurangi emisi kendaraan bermotor lebih tinggi daripada tumbuhan pucuk merah (Syzygium oleana).

\section{UCAPAN TERIMAKASIH}

Ucapan terima kasih kepada Universitas PGRI Adibuana Surabaya yang telah memberikan kesempatan kepada peneliti untuk melakukan penelitian dan Saudara Annisa Rifka Alifia yang telah melakukan editing terhadap artikel ini.

\section{REFERENSI}

Agustin, M. D (2018). Penurunan kadar SO2 dan NO2 menggunakan tumbuhan. Skripsi Teknik Lingkungan-FTSPUniversitas PGRI adibuana Surabaya

Hardiyanti (2017). Akumulasi logam berat timbal $(\mathrm{Pb})$ danpengaruhnya pada daun glodokan tiang (polyalthia longifolia) di jalan a.p. pettarani kota Makassar. Skripsi Fakultas Saint dan Teknologi UIN alaudin Makassar

Kondorura, C. F (2018). Nalisis kapasitas ruang terbuka hijau balai kota makassar dalam mereduksi emisi kendaraan bermotor. Skripsi departemen Teknik lingkungan Fakultas teknik Universitas Hasanuddin.

Mirawati, B., Muhlis., Prapti S. (2016). Efektivitas beberapa tanaman hias dalam menyerap timbal $(\mathrm{Pb})$ di udara. Jurnal penelitian IPA (JPPIPA) Volume 2 No. 1

Momongan, J.F., Pierre, H.G., Veronica, A.K. (2016) . Efektivitas jalur hijau dalam 
Hendra Purwanto Utomo dan Rhenny Ratnawati : Efektivitas Vegetasi untuk Penurunan Kadar Karbon Monoksida (CO) dan Nitrogen Dioksida $\left(\mathrm{NO}_{2}\right)$

menyerap emisi gas rumah kaca di Kota Manado. Perencaan wilayah \& kota Universitas Sam Ratulangin. Manado

Prodjosantoso (2011). Kimia lingkungan. Kanisius Yogyakarta

Rachmaniyah, Imam, T. (2017). Efektivitas program car free day terhadap penurunan kadar NOx Udara. Global Health Science, Volume 2 issue 4

Riani, P.D (2017). Gambaran kualitas udara ambien (SO2, NO2, TSP) dalam keluhan subyektif gangguan pernapasan pada pedagang yang tetap di terminal bus kamp ng Rambutan Jakarta Timur tahun 2017. Skripsi Fakultas kedokteran dan ilmu kesehatan Universitas islam Negeri (UIN) syarif Hidayatullah, Jakarta

Santoso, Suci Normaliani. 2011. Penggunaan Tumbuhan Sebagai Pereduksi Pencemaran Udara . Teknik Lingkungan-FTSP-ITS

Wakhid, muhammad umar (2018). Analisis dampak emisi gas buang kendaraan bermotorco di UIN Raden Intan Lampung. Fakultas tarbiyah dan keguruan Universitasislam Negeri Raden Intan Lampung. 